\title{
Age and gender differences in the prevalence of chronic diseases and atherosclerotic cardiovascular disease risk scores in adults in Riyadh city, Saudi Arabia
}

AlJohara M. AlQuaiz, MD, MRCGP, Ambreen Kazi, MCPS, FCPS, Abdulaziz A. Alodhayani, MD, SBFM, Aljohara Almeneessier, MD, ABFM, Khaled M. AlHabeeb, BDS, Amna R. Siddiqui, FCPS, PhD.

\begin{abstract}
الأهداف: تقييم العمر و اختلاف الجنس في انتشار الأمراض المزمنة وتحديد

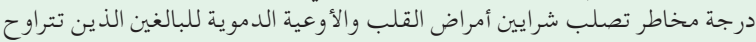
أعمارهم بين 75-30 سنة في مدينة الرياض، المملكة العربية السعودية .

المنهجية : أجريت دراسة مقطعية، مبنية على استبيان مع 2997 امرأة ورجل

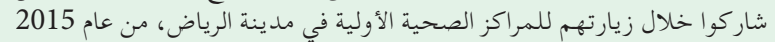

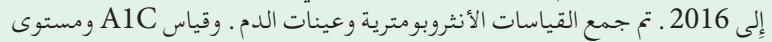

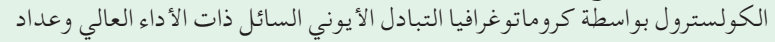

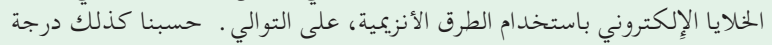

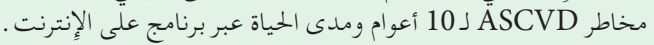

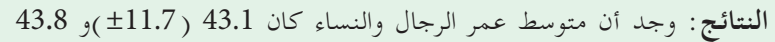

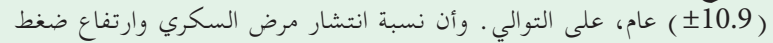

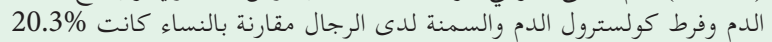

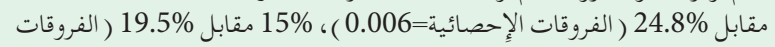

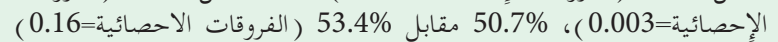

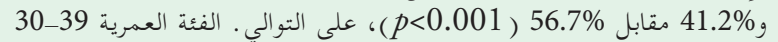

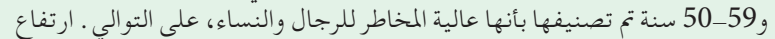

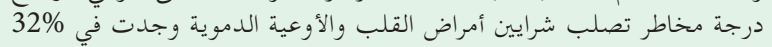

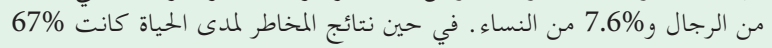
51\% على التوالي.

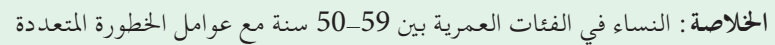

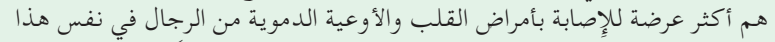

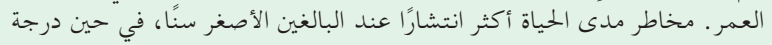

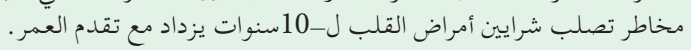

Objectives: To evaluate age and gender differences in the prevalence of chronic diseases and to calculate atherosclerotic cardiovascular disease (ASCVD) risk scores in adults aged 30-75 years in Riyadh city, Saudi Arabia.

Methods: This cross-sectional, interview-based study was conducted with 2997 men and women, visiting primary health care centers in Riyadh, during the years 2015 to 2016. Serum glycosylated hemoglobin and lipid levels were measured by ion-exchange high-performance liquid chromatography and fully automated analyzer using enzymatic methods, respectively. The 10 -year and lifetime ASCVD risk scores were calculated using an online calculator.

Results: The mean age of men was $43.1( \pm 11.7)$ and women was $43.8( \pm 10.9)$ years. Prevalence rates of diabetes mellitus, hypertension, hypercholesterolemia, and obesity in men versus women were $20.3 \%$ versus $24.8 \%$ ( $p=0.006$ ), $15 \%$ versus $19.5 \%$ ( $p=0.003$ ), $50.7 \%$ versus $53.4 \% \quad(p=0.16)$, and $41.2 \%$ versus $56.7 \%$ $(p<0.001)$, respectively. Majority of men and women with chronic diseases belonged to the age groups $30-$ 39 and 50-59 years, respectively. High 10-year ASCVD risk was found in $32 \%$ men and $7.6 \%$ women, whereas lifetime risk was present in $67 \%$ and $51 \%$, respectively.

Conclusion: Women in the age group 50-59 years, with multiple risk factors are at a greater risk of developing cardiovascular diseases than men of same age. Young adults were at more risk for lifetime ASCVD, whereas the 10-year ASCVD risk increased with increasing age.

Keywords: gender, age, non-communicable diseases, Saudi Arabia

Saudi Med J 2021; Vol. 42 (5): 526-536

doi: 10.15537/smj.2021.42.5.20200684

From the Princess Nora Bent Abdullah Chair for Women's Health Research (AlQuaiz, Kazi, Almeneessier, AlHabeeb, Siddiqui), Deanship of Research Chairs Program, and from the Department of Family \& Community Medicine (AlQuaiz, Kazi, AlOdhayani), College of Medicine, King Saud University Medical City, King Saud University, Riyadh, Kingdom of Saudi Arabia.

Received 26th November 2020. Accepted 15th March 2021.

Address correspondence and reprint request to: Dr. Ambreen Kazi, King Saud University, Riyadh, Kingdom of Saudi Arabia. E-mail:akamran@ksu.edu.sa

ORCID ID: http://orcid.org/0000-0002-6807-8555 
$\mathrm{N}$ on-communicable diseases (NCDs) are a global public health problem, which includes cardiovascular diseases (CVDs), diabetes mellitus (DM), obesity, lipid disorders, and respiratory and musculoskeletal diseases. ${ }^{1}$ It has been reported that the total number of NCD-related deaths accounted for $73.4 \%$ of global causes of deaths and had increased by $22.7 \%$ from the year 2007-2017, primarily due to CVDs. ${ }^{1}$ Non-communicable diseases are responsible for $78 \%$ of all deaths in the Kingdom of Saudi Arabia (KSA), with 46\% being CVD-related deaths. ${ }^{2}$ The increasing trend in non-communicable diseases in KSA is associated with increase in disability and negative impact on quality of life. ${ }^{3}$ In the United States, the number of deaths attributed to CVDs accounted for $33 \%$ of all-cause mortality occurring in the younger adult population aged $<75$ years in 2008. ${ }^{4}$ In 2015 , CVD was reported as the topmost leading cause of mortality, with a death rate of $43.8 \%$, and by the year 2035, the medical cost has been estimated to reach $\$ 368$ billion. ${ }^{5}$

In the Saudi national-level survey conducted during 2007-2009, Al-Rubeaan reported that the prevalence rates of metabolic syndrome were $31.6 \% \quad(34.4 \%$ in men versus $29.2 \%$ in women) according to the International Diabetes Foundation (IDF) and 39.9\% (45\% in men versus $35.4 \%$ in women) in National Cholesterol Education Program-Adult Treatment Panel III (NCEP ATP III) criteria. ${ }^{6}$ The Centralized Pan-Middle East Survey (CEPHEUS) on the under treatment of hypercholesterolemia in 2010 in the Arabian Gulf also reported the presence of obesity with a prevalence rate of 53\%, DM 76\%, metabolic syndrome $41 \%$, hypertension (HTN) 70\%, and smoking 13\%. Approximately $78 \%$ of CEPHEUS participants had very high atherosclerotic cardiovascular disease (ASCVD) risk status with 3 or more major risk factors, with $75 \%$ of Saudis (2449/3259) belonging to the very high ASCVD risk status. ${ }^{7}$ It was estimated that by controlling the major risk factors, including smoking, alcohol consumption, salt intake, obesity, and high blood pressure and glucose levels, the NCD-related premature mortality (death between 30 and 70 years of age) over 15 years, during 2010-2025, can be reduced

Disclosure. Authors have no conflict of interests, and the work was not supported or funded by any drug company. The study was funded by the Deanship of Scientific Research, Research Chairs program, King Saud University Medical city, King Saud University, Riyadh, Saudi Arabia. by $22 \%$ in men and $19 \%$ in women. ${ }^{8}$ In addition to body mass index (BMI), central obesity, based on waist circumference, is a reliable indicator for predicting CVD risk. ${ }^{9}$ Study from KSA have found that 2 or more than 2 risk factors for metabolic syndrome were higher among men $(46.8 \%)$ compared to women (40.5). The study also found that waist circumference cut-offs values (92 $\mathrm{cms}$ for men, and $87 \mathrm{cms}$ for women) were better than waist-hip ratio and the BMI in predicting metabolic syndrome in the local population. ${ }^{10}$

Atherosclerotic cardiovascular diseases are considered as the leading cause of mortality among women due to gender-specific risk factors such as menarche, menopause, parity, and pregnancy-related diseases, and approximately $40 \%$ of them have a lifetime risk of developing ASCVDs after age 50 years. ${ }^{11}$ To estimate the lifetime risk of developing ASCVDs, a study conducted on 8000 cohort population of the Framingham study group who were free of CVD and aged 50 years reported an estimated lifetime risk of $51.7 \%$ for men and $39.2 \%$ for women. ${ }^{12}$ The lifetime risk increased in the presence of one or more risk factors. ${ }^{12}$ Another study conducted on a cohort population of South Asian origin estimated the lifetime risk of developing ASCVDs as 79\% for men and $70 \%$ for women, with the 10 -year estimated risk of $12.6 \%$ for men and $5.1 \%$ for women. ${ }^{13}$ In the KSA, the pattern of NCD has changed since the past 2 decades due to changes in the Saudi living standards. There has been a tremendous increase in tobacco use, physical inactivity, and obesity among men and women. ${ }^{3}$ The incidence and prevalence of a disease are core indicators of public health, which guide in deciding upon issues such as which diseases are most common and what health problems warrant priority. ${ }^{1,2}$ Therefore, this study was conducted to determine the prevalence of chronic diseases, including DM, HTN, hypercholesterolemia, and obesity, according to age and gender and also to estimate the 10-year and lifetime ASCVD risk scores among Saudi men and women aged 30-75 yeas in Riyadh city, Saudi Arabia.

Methods. This study was conducted in 18 randomly (https://www.random.org/) selected primary health care centers belonging to 5 administrative regions in Riyadh city, 2015-2016. According to the KSA population statistics, 218,000 people were living in Riyadh during the study period. The study was well-advertised in the vicinity of the PHCC, so that maximum number can participate. Posters and banners were placed at all major places, like malls, mosques, schools, and so forth. 
Patients and their attendants visiting the PHCC were invited to participate in the study. The daytime data collection was colliding with offices timings; therefore, data collectors separately visited private offices and educational institutes so to include the working population.

The inclusion criteria were all Saudi adults aged between 30 and 75 years who were permanent residents of Riyadh city. The response rate was encouraging, with $<5 \%$ refusal rate. ${ }^{17}$ Forms were discarded due to incomplete information and 2997 participants were included in the final analysis. Blood samples for analyzing the lipid profile and glycosylated hemoglobin (HbA1c) levels were collected according to the standard protocol, and laboratory analysis was conducted at King Khalid University Hospital, Riyadh, KSA.

The study was conducted according to the principles of Helsinki Declaration. The study protocol was approved by the Institutional Review Board, King Saud University (E-12-658) and the Institutional Review Board of the Ministry of Health, KSA (IRB ID MOH0151). A written informed consent was obtained from participants after explaining the purpose of the study with emphasis on voluntary participation, anonymity, and confidentiality.

Anthropometric and blood pressure measurements. The anthropometric indices included weight, which was measured using an electronic scale (Secca 220, Hamburg, Germany, 2009), and height, which was measured using the standard method with a stadiometer. Body mass index was calculated by using the formula weight in kilograms/height in square meters. Waist circumference (WC) was used to determine the central obesity. It was measured using a measuring tape at the midpoint between the lowest rib and the top of the hip bone (iliac crest). Central obesity for men and women was defined as a WC of $>90$ and $>80 \mathrm{~cm}$, respectively, and high central obesity was defined as $>102$ and $>88 \mathrm{~cm}$, respectively. ${ }^{14}$ Two blood pressure readings were taken using the oscillometric method with the participant in an upright position, according to the instruction manual (Omron-5 Series TM Blood Pressure Monitor Model BP742-China 2010). The average of both readings was computed.

Measurement of HbA1c level. Hemoglobin A1c level was measured at the central laboratory of King Khalid University Hospital by the ion-exchange high-performance liquid chromatography (HPLC) method using Tosoh G8 -90SL or the Tosoh G8 HPLC Analyzer (Tosoh Bioscience, Inc, USA). The coefficient of variation $(\mathrm{CV})$ was $<2 \%$. Two HbA1c cut-off points were taken for patients with previously physiciandiagnosed DM, the control HbA1C level was taken as $\leq 7 \%$, and for those with newly diagnosed DM, the HbA1C level was taken as $\leq 6.5 \%$.

Measurement of lipids. Serum levels of total cholesterol, low-density lipoprotein (LDL), highdensity lipoprotein (HDL)-cholesterol, and triglycerides (TGs) were measured in millimoles per liter using a fully automated analyzer (Siemens Dimension RxL, Germany) using enzymatic methods. The intra-assay and inter-assay CVs were 0.84 and 1.30 for total cholesterol and 1.9 and 2.1 for HDL-cholesterol, respectively. The respective intra-assay and inter-assay $\mathrm{CV}$ s were 0.84 and 1.30 for total cholesterol, 1.9 and 2.1 for HDL, and 0.4 and 1.0 for TGs. low density lipoprotein-cholesterol was calculated using the Friedewald equation:

$$
[\mathrm{LDL}-\mathrm{C}=\mathrm{TC}-(\mathrm{HDL}-\mathrm{C})-\mathrm{TG} / 5] .^{15}
$$

Atherosclerotic cardiovascular diseases risk scores. The ASCVD include patients with a history of acute coronary syndrome, myocardial infarction, stable angina, coronary/other arterial revascularization, stroke, transient ischemic attack, or peripheral arterial disease from atherosclerosis. ${ }^{16}$ The online calculation requires information regarding age, gender, race, systolic blood pressure (at the time of the interview), treatment for HTN (yes/no), diabetes (yes/no), smoking (yes/ no), total blood cholesterol, and HDL levels for each participant. ${ }^{16}$

Statistical analysis. The data were analyzed using Statistical Package for Social Sciences (SPSS) ${ }^{\oplus}$ version 21) Armonk, NY. IBM Corp. USA. Descriptive statistics consisting of frequency percentages for categorical variables and mean with standard deviation for continuous variables were calculated. Pearson Chi-square test was utilized to measure the difference in categorical variables. Bivariate analysis was conducted to calculate the unadjusted odds ratio and $95 \%$ confidence interval (CI) between gender and chronic diseases. The lifetime and 10-year ASCVD risk scores were calculated according to the free online program available at https://tools.acc.org/ldl/ascvd_risk_estimator/index. html\#!/calulate/estimator/. The ASCVD risk score calculator measures the lifetime and 10-year risk scores. The lifetime risk score calculates ASCVD scores for individuals aged 20-59 years and was divided into 2 categories based on less than or $\geq 39 \%$ risk estimate. The 10-year ASCVD risk score was calculated for individuals aged 40-75 years, with a cut-off value of 7.5 to identify high risk individuals. ${ }^{14}$ The level of statistical significance was set as $p<0.05$. 
Table 1 - Sociodemographic characteristics and anthropometric measurements of Saudi males and females in Riyadh city, Saudi Arabia.

\begin{tabular}{|c|c|c|c|}
\hline Characteristics & $\begin{array}{c}\text { Males } \\
(\mathrm{n}=968)\end{array}$ & $\begin{array}{c}\text { Females } \\
(\mathrm{n}=2029)\end{array}$ & $P$-value \\
\hline $\begin{array}{c}\text { Age (years) } \\
30-39 \\
40-49 \\
50-59 \\
60-75\end{array}$ & $\begin{array}{l}435(44.9) \\
275(28.4) \\
151(15.6) \\
107(11.1)\end{array}$ & $\begin{array}{l}838(41.3) \\
577(28.4) \\
392(19.3) \\
222(10.9)\end{array}$ & $<0.07$ \\
\hline $\begin{array}{l}\text { Participants education } \\
\text { Secondary \& below } \\
\text { University \& above }\end{array}$ & $\begin{array}{l}254(26.2) \\
714(73.8)\end{array}$ & $\begin{array}{c}1153(56.8) \\
876(43.2)\end{array}$ & $<0.01$ \\
\hline $\begin{array}{l}\text { Spouse education }(n=2749) \\
\text { Intermediate } \& \text { below } \\
\text { University \& above }\end{array}$ & $\begin{array}{l}392(45.3) \\
474(54.7)\end{array}$ & $\begin{array}{l}1122(59.6) \\
761(40.4)\end{array}$ & $<0.01$ \\
\hline $\begin{array}{l}\text { Participants occupation } \\
\text { Working } \\
\text { Not working }\end{array}$ & $\begin{array}{l}852(88.0) \\
116(12.0)\end{array}$ & $\begin{array}{c}858(42.3) \\
1171(57.7)\end{array}$ & $<0.01$ \\
\hline $\begin{array}{l}\text { Spouse occupation }(n=2749) \\
\text { Working } \\
\text { Not working }\end{array}$ & $\begin{array}{l}632(73.0) \\
234(27.0)\end{array}$ & $\begin{array}{c}1322(70.2) \\
561(29.8)\end{array}$ & $<0.01$ \\
\hline $\begin{array}{l}\text { Housing type } \\
\text { Traditional Arabic house } \\
\text { Apartment } \\
\text { Villa }\end{array}$ & $\begin{array}{c}51(5.3) \\
341(35.2) \\
576(59.5)\end{array}$ & $\begin{array}{c}273(13.5) \\
47423.4) \\
1280(63.1)\end{array}$ & $<0.01$ \\
\hline $\begin{array}{l}\text { Monthly income } S A R(n=2661) \\
\quad \leq 10,000 \\
\quad>10,000\end{array}$ & $\begin{array}{l}320(33.9) \\
623(66.1)\end{array}$ & $\begin{array}{l}986(57.4) \\
732(42.6)\end{array}$ & $<0.01$ \\
\hline $\begin{array}{l}\text { Current smoker } \\
\text { Yes } \\
\text { No }\end{array}$ & $\begin{array}{l}268(27.7) \\
700(72.3)\end{array}$ & $\begin{array}{c}44(2.2) \\
1985(97.8)\end{array}$ & $<0.01$ \\
\hline
\end{tabular}

${ }^{*} P$-values calculated to measure significant difference between men and women using the Chi-square test
Results. Table 1 shows the sociodemographic profile of the 2997 participants, comprising of 968 men, and 2029 women. There was no significant difference in the mean age of men $(43.1 \pm 11.7)$ and women $(43.8$ $\pm 10.9)$ years $(p=0.07)$. Approximately $65 \%(n=149)$ of men reported smoking for $>10$ years, whereas women, although few, had a more recent history of smoking. Most men $(n=120)$ were smoking $\geq 20$ cigarettes per day, whereas $30 \%$ of them were past smokers and had quit smoking.

Diabetes mellitus. Differences in prevalence by age and gender. The overall prevalence of DM (physician diagnosed and on screening) was $23.4 \%(n=692)$, with women showing a higher prevalence than men (Table 2). Out of the $20 \%$ cases with physician diagnosed cases, $11 \%$ were showing uncontrolled diabetes ( $\mathrm{HbA} 1 \mathrm{c}$ levels $>7 \%$,). A small percentage (3\%) of cases were identified as diabetic on screening (based on $\mathrm{HbAlc}$ levels $>6.5 \%$ ). The unadjusted odds ratio for total prevalence (diagnosed and on screening) revealed that women were $1.30(1.16,1.56 ; p=0.006)$ times at higher odds for having diabetes. Figure 1 shows that majority of diabetic men $(30.3 \%)$ were in the age bracket of $40-49$ years, whereas most women $(35.4 \%)$ belonged to age group $50-59$ years. A significant percentage $(20.5 \%, n=474)$ of participants were found with prediabetes (HbAlc level $5.7 \%-6.4 \%$ ), with a greater number of men than women $(22.7 \%$ versus $19.9 \%)$. In contrast to diabetics, the majority of prediabetics belonged to the age group of $30-39$ years (men $39 \%$ versus women $30 \%, p=0.04$ ).

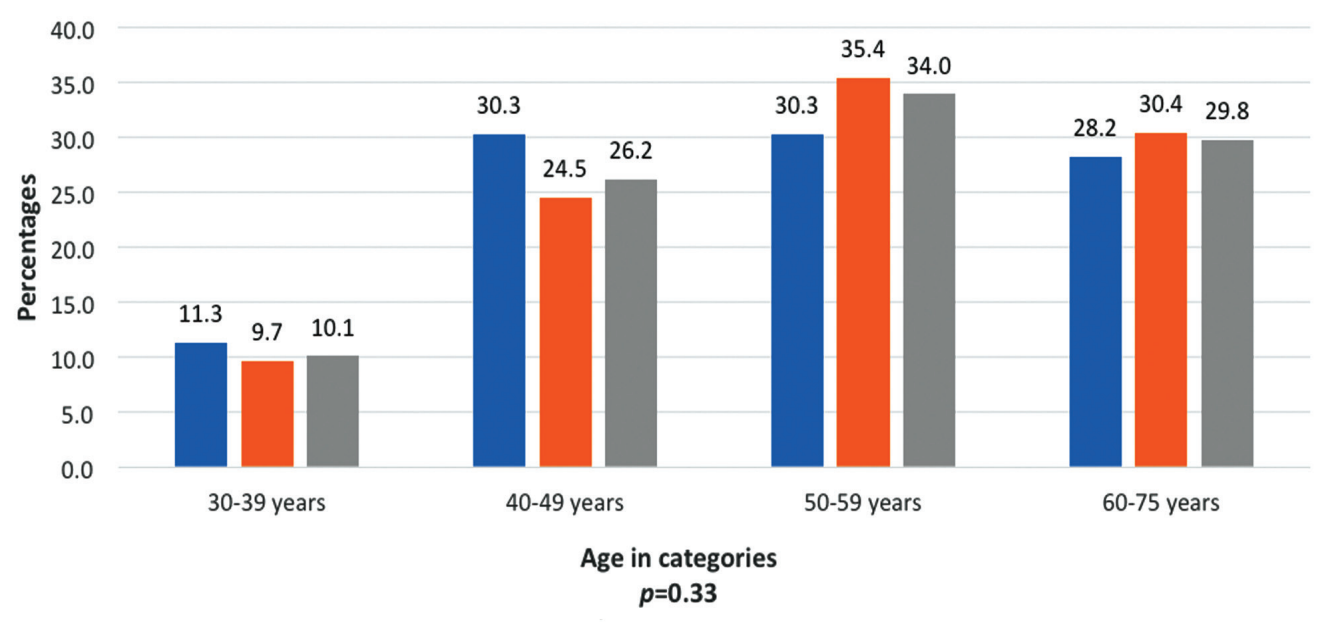

- Male $\quad$ Female $\quad$ Total

Figure 1 - Prevalence of diabetes mellitus in Saudi men and women by age categories in Riyadh city, Saudi Arabia. 
Age and gender differences in chronic diseases ... AlQuaiz et al

Table 2 - Prevalence of chronic diseases (diagnosed and screened) ${ }^{a}$ in Saudi males and females in Riyadh city, Saudi Arabia.

\begin{tabular}{|c|c|c|c|c|}
\hline Disease & \multicolumn{2}{|c|}{ Diagnosed and screened } & & Total prevalence \\
\hline \multirow[t]{2}{*}{ Diabetes mellitus } & \multicolumn{2}{|c|}{$\begin{array}{c}\text { Diagnosed cases }{ }^{\mathrm{b}} \\
\text { Males }=162, \text { Females }=438\end{array}$} & \multirow{2}{*}{$\begin{array}{l}\text { Raised HbAlc on } \\
\text { screening } \\
(\geq 6.5)\end{array}$} & \multirow{2}{*}{$\begin{array}{c}\text { Total prevalencec }(\mathrm{N}=2962) \\
\text { (both diagnosed and screened) } \\
\text { Males }=961, \text { Females }=2001\end{array}$} \\
\hline & $\begin{array}{l}\text { Controlled } \\
\text { HbAlc } \leq 7.0\end{array}$ & $\begin{array}{l}\text { Uncontrolled } \\
\text { HbA1c }>7.0\end{array}$ & & \\
\hline Male & $70 \quad(7.3)$ & $92(9.6)$ & $33(4.1)$ & $195(20.3)$ \\
\hline Female & $203(10.1)$ & $235(11.8)$ & $59(2.9)$ & $497(24.8)^{*}$ \\
\hline Total & $273(9.3)$ & $327(11.0)$ & $92(3.1)$ & $692(23.4)$ \\
\hline \multirow[t]{2}{*}{ Hypertension } & \multicolumn{2}{|c|}{$\begin{array}{c}\text { Diagnosed cases } \\
\text { Males }=145, \text { Females }=396\end{array}$} & $\begin{array}{l}\text { Raised blood pressure } \\
\text { reading on screening only }\end{array}$ & $\begin{array}{l}\text { Total prevalence }{ }^{c}(\mathrm{~N}=2987) \\
\text { (only physician diagnosed) }\end{array}$ \\
\hline & $\begin{array}{c}\text { Controlled } \\
<140 \text { and }<90\end{array}$ & $\begin{array}{c}\text { Uncontrolled } \\
\geq 140 \text { or } / \text { and } \geq 90\end{array}$ & $\geq 140$ or/and $\geq 90$ & $\begin{array}{c}\text { Males }=968, \text { Females }=2029 \\
\text { Total }=2987\end{array}$ \\
\hline Males & $63(6.5)$ & $82(8.5)$ & $134(16.3)$ & $145(15.0)$ \\
\hline Females & $225(11.1)$ & $171(8.4)^{* *}$ & $148(9.1)$ & $396(19.5)$ \\
\hline Total & $288(9.6)$ & $253(8.4)$ & $282(11.5)$ & $541(18.1)$ \\
\hline \multirow[t]{3}{*}{ Hypercholesterolemia } & \multirow{2}{*}{\multicolumn{2}{|c|}{$\begin{array}{c}\text { Diagnosed cases } \\
\text { Males }=174, \text { Females }=516\end{array}$}} & \multirow{3}{*}{$\begin{array}{l}\text { Raised cholesterol levels } \\
\text { on screening } \\
\geq 5.2 \mathrm{mmol} / \mathrm{L}\end{array}$} & \multirow{3}{*}{$\begin{array}{l}\text { Total prevalence }(\mathrm{N}=2985) \\
\text { (both diagnosed } \& \text { screened) } \\
\text { Males }=965, \text { Females }=2020\end{array}$} \\
\hline & & & & \\
\hline & $\begin{array}{l}\text { Controlled } \\
<5.2 \mathrm{mmol} / \mathrm{L}\end{array}$ & $\begin{array}{l}\text { Uncontrolled } \\
\geq 5.2 \mathrm{mmol} / \mathrm{L}\end{array}$ & & \\
\hline Males & $98(10.1)$ & $76(7.9)$ & $315(32.6)$ & $489(50.7)$ \\
\hline Females & $236(11.6)$ & $280(13.9)^{* * *}$ & $563(27.9)$ & $1079(53.4)$ \\
\hline Total & $334(11.1)$ & $356(11.9)$ & $878(29.4)$ & $1568(52.5)$ \\
\hline Body mass index $x^{\neq}$ & \multicolumn{2}{|c|}{$\begin{array}{c}\text { Overweight }^{\mathrm{b}} \\
\mathrm{BMI} \geq 25.0-\leq 29.99\end{array}$} & $\begin{array}{l}\text { Obesity }^{\mathrm{b}} \\
\mathrm{BMI} \geq 30\end{array}$ & $\begin{array}{c}\text { Total prevalence }(\mathrm{N}=2997) \\
\text { Males }=968, \text { Females }=2029\end{array}$ \\
\hline Male & \multicolumn{2}{|c|}{$363(37.5)$} & $399(41.2)$ & $762(78.7)$ \\
\hline Female & \multicolumn{2}{|c|}{$587(28.9)$} & $1149(56.7)^{\S}$ & $1739(85.7)$ \\
\hline Total & \multicolumn{2}{|c|}{$950(31.7)$} & $1548(51.7)$ & $2504(83.6)$ \\
\hline Waist circumference & \multicolumn{2}{|c|}{$\begin{array}{c}\text { Central obesity } \\
\text { Male }>90-<102 \mathrm{cms}, \\
\text { Female }>80-<88 \mathrm{cms}\end{array}$} & $\begin{array}{l}\text { High central obesity } \\
\text { Male } \geq 102 \mathrm{cms} \\
\text { Female } \geq 88 \mathrm{cms}\end{array}$ & $\begin{array}{c}\text { Total prevalencec }^{c}(\mathrm{~N}=2997) \\
\text { Males }=968 \\
\text { Females }=2029\end{array}$ \\
\hline Male & \multicolumn{2}{|c|}{$256(26.4)$} & $286(29.5)$ & $542(56)$ \\
\hline Female & \multicolumn{2}{|c|}{$435(21.4)^{\ddagger}$} & $1252(61.7)^{\dagger}$ & $1687(83.1)$ \\
\hline Total & \multicolumn{2}{|c|}{$691(23.0)$} & $1538(51.3)$ & $2229(74.4)$ \\
\hline
\end{tabular}

${ }^{a}$ Diagnosed cases were physician diagnosed and those identified on screened were identified on conducting blood tests, ${ }^{b}$ Row percentage ${ }^{c}$ Column percentage, ${ }^{\mathrm{d}}$ Missing data: $\mathrm{DM}$ males $=7$ and females $=28$; High cholesterol males $=3$ and females $=8$; Hypertriglyceridemia males $=12$ and females $=30$, $p$-values calculated using the Chi square test, ${ }^{*}$ Total prevalence of diabetes mellitus in females compared to males: odds ratio $(95 \% \mathrm{CI})=1.30(1.16,1.56)$, $p=0.006,{ }^{* *}$ Uncontrolled cases of hypertension in females compared to males: odds ratio $(95 \% \mathrm{CI})=0.57(0.39,0.84), p=0.004$, ${ }^{* * *}$ Uncontrolled cases of hypercholesterolemia in females compared to males: odds ratio $(95 \% \mathrm{CI})=1.60(1.12,2.25), p=0.008$, ${ }^{5}$ Prevalence of obesity $(\mathrm{BMI} \geq 30)$ in females compared to males: odds ratio $(95 \% \mathrm{CI})=2.02(1.63,2.50), p<0.001$, * Prevalence of central obesity in females compared to males: odds ratio $(95 \% \mathrm{CI})=$

$2.12(1.72,2.61), p<0.001, \dagger$ Prevalence of high central obesity in females compared to males: odds ratio $(95 \% \mathrm{CI})=5.45(4.50,6.60), p<0.001$

Overall, $57.7 \%(\mathrm{n}=1730)$ of participants had a positive family history of DM. The mean duration with DM was $8.86( \pm 7.4)$ years, with a range of $1-45$ years. Although women had a higher prevalence of DM and positive family history, $8 \%$ of them were not taking any treatment (versus $4 \%$ men).

Hypertension. Differences in prevalence by age and gender. The overall prevalence of physician diagnosed HTN was lower than that of DM $(18.1 \%$ versus $23.4 \%$ ), with women showing better control than men [UOR $0.57(0.39,0.84) \quad p<0.004]$ (Table 2). More men were detected with HTN as compared to women
(16.3\% versus 9.1\%). Age distribution found that HTN in men was more common in the age group of 40-49 years $(28 \%)$, whereas, in women, the number peaked between ages $50-59$ years (33\%). Pre-HTN was almost twice among men than that in women $(42.9 \%$ men versus $21.2 \%$ women). Higher number of women reported positive family history $(57 \%$ versus $40 \%)$ and average number of years with HTN $[8.3( \pm 7.1)$ versus $6.4( \pm 6.1)]$ as compared to men.

Hypercholesterolemia. Differences in prevalence by age and gender. The overall prevalence of hypercholesterolemia was approximately 50\%, with 
no significant difference between men and women $(p=0.16)$ (Table 2). Among the diagnosed cases, the percentage of women with high cholesterol exceeded that of men ( $14 \%$ versus $8 \%)$, whereas, on screening it was opposite with more number of men than women (32.6\% versus $27.9 \%)$. Age distribution found that amongst men $70 \%$ were aged $30-49$ years, whereas, amongst 50-75 years, the proportion of women exceeded that of men (25.6\% versus $16.6 \%)$. Positive family history (men $18.5 \%$ versus women $36.5 \%$ ) and duration with hypercholesterolemia [men $4.3( \pm 4.2)$ versus women $5.7( \pm 5.2)$ years] were reported more by women in comparison to men. Amongst, physiciandiagnosed cases, approximately $13 \%$ of participants were not taking any treatment (no significant gender difference, $p=0.15$ ).

Triglycerides and HDL-cholesterol levels. More men had elevated TG levels in comparison to women (48.6\% vs $29.1 \%$ ). Regarding age distribution, a higher proportion of men were aged $30-39$ years ( $46.7 \%$ versus $33.4 \%$ ), whereas $24.7 \%$ of women were in age group $50-59$ years compared to $14.6 \%$ of men $(p<0.001)$. A significantly high percentage of men had low HDL levels in comparison to women. (30\% versus $8.5 \%$ ). The age distribution followed the same trend as for other markers, with more men in the age group 30-39 years, whereas the proportion of women was higher in the age group $40-49$ years (27\% women versus $12 \%$ men) $(p<0.001)$.

Differences in overweight and obesity by age and gender. Anthropometric measurements revealed that overweight was more common among men $(37.5 \%$ versus $28.9 \%$ ), whereas obesity was more common among women (41.2\% versus $56.7 \%$ ), respectively, with $9 \%$ of them suffering from extreme obesity (BMI $\geq 40 \mathrm{~kg} / \mathrm{m}^{2}$ ). Waist circumference measurements showed that high central obesity was more common among women than among men $(29.5 \%$ men versus $61.7 \%$ women) (Table 2). Overweight was more common among the young age categories in both men and women, although the difference was not statistically significant $(p=0.22)$. Figure 2 shows the that obese men are more in number in the age category of 30-39 as compared to women, and it is vice versa for the age category 50-59 years. However, this difference was not statistically significantly different $(p=0.10)$. However, age distribution for central obesity (men $\geq 90$, women $\geq 80 \mathrm{cms}$ ) found no significant difference in proportion of men and women by age.

Lifetime and 10-year ASCVD risk scores. The lifetime ASCVD risk scores were calculated for 1918 study participants (639 men and 1279 women) aged 30-59 years, whereas the 10-year ASCVD risk scores were calculated for 964 participants $(324$ men and 640 women) aged 40-75 years. The lifetime ASCVD risk score found that $56 \%(\mathrm{n}=1081)$ of participants belonging to 30-59 years had high risk (>39\%). The proportion of men with high lifetime risk is more compared to women $(p<0.001)$ (Table 3). Regarding age distribution, almost $50 \%$ of men and women with high-risk scores belonged to the age group 30-39 years; however, specifically in the age group 50-59 years,
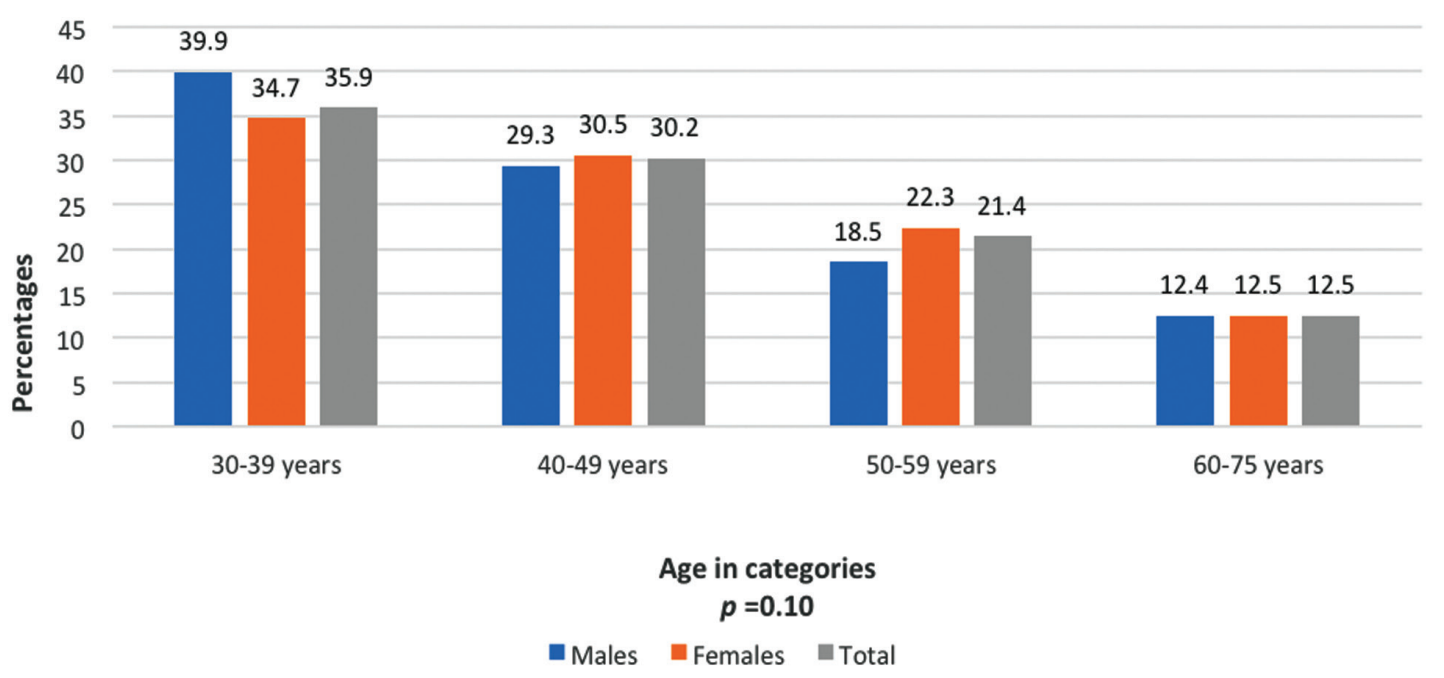

Figure 2 - Prevalence of central obesity in Saudi men and women by age categories in Riyadh city, Saudi Arabia. 
Age and gender differences in chronic diseases ... AlQuaiz et al

Table 3 - Proportion of Saudi men and women with high 10-year and lifetime atherosclerotic cardiovascular disease (ASCVD) risk scores by age category in Riyadh city, Saudi Arabia.

\begin{tabular}{|c|c|c|c|}
\hline \multirow[t]{2}{*}{ ASCVD risk } & \multicolumn{2}{|c|}{ Age in years } & \multirow[b]{2}{*}{ Total } \\
\hline & Males & Females & \\
\hline $\begin{array}{l}\text { Ten year ASCVD risk }{ }^{a}(>7.5) \\
\text { males }=324, \text { females }=640 \quad(n=964)\end{array}$ & $104(32.1)$ & $49(7.6)$ & $153(15.9)^{*}$ \\
\hline \multicolumn{4}{|l|}{ Age (years) } \\
\hline $40-49$ & $6(12.2)$ & $3(6.1)$ & $40(81.6)$ \\
\hline $50-59$ & $35(33.7)$ & $20(19.2)$ & $49(47.1)$ \\
\hline $60-75$ & $41(26.8)$ & $23(15.0)$ & $89(58.2)$ \\
\hline $\begin{array}{l}\text { Odds ratio between gender and } 10 \text { year } \\
\text { ASCVD risk scores }\end{array}$ & \multicolumn{2}{|c|}{$5.70(3.93,8.28)$} & \\
\hline $\begin{array}{l}\text { Lifetime ASCVD riskb }(>39 \%) \\
\text { males }=639, \text { females }=1279 \quad(n=1918)\end{array}$ & $430(67.3)$ & $651(50.9)$ & $1081(56.4)$ \\
\hline \multicolumn{4}{|l|}{ Age (years) } \\
\hline $30-39$ & 238 (36.6) & $284(43.6)$ & $129(19.8)$ \\
\hline $40-49$ & $143(33.3)$ & $226(52.6)$ & $61(14.2)$ \\
\hline $50-59$ & $381(35.2)$ & $510(47.2)$ & $190(17.6)$ \\
\hline $\begin{array}{l}\text { Odds ratio between gender and lifetime } \\
\text { ASCVD risk scores }\end{array}$ & \multicolumn{2}{|c|}{$1.98(1.63,2.42)$} & \\
\hline \multicolumn{4}{|c|}{ 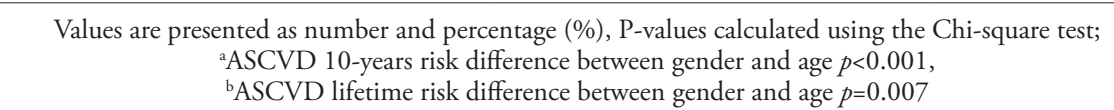 } \\
\hline
\end{tabular}

Table 4 - Proportion of Saudi men and women with number of risk factors by age in Riyadh city, Saudi Arabia.

\begin{tabular}{|c|c|c|c|c|c|c|}
\hline \multirow{2}{*}{$\begin{array}{l}\text { Number of } \\
\text { risk factors } \\
\text { by age* }\end{array}$} & \multirow[t]{2}{*}{ Gender } & \multicolumn{4}{|c|}{$\begin{array}{c}\text { Age in categories } \\
\mathbf{n}(\%)\end{array}$} & \multirow{2}{*}{$\begin{array}{c}\text { Total }(\mathrm{N}=2032) \\
\text { Males }=690 \\
\text { Females }=1342\end{array}$} \\
\hline & & $30-39$ & $40-49$ & $50-59$ & $60-75$ & \\
\hline \multirow[t]{2}{*}{1} & Males & $152(59)$ & $59(23)$ & $38(15)$ & $8(3)$ & $257(40.3)$ \\
\hline & Females & $352(55)$ & $206(32)$ & $71(11)$ & $10(2)$ & $639(65.5)$ \\
\hline \multirow[t]{2}{*}{2} & Males & $127(53)$ & $68(28)$ & $30(12)$ & $17(7)$ & $242(37.9)$ \\
\hline & Females & $84(36)$ & $80(35)$ & $39(17)$ & $28(12)$ & $231(23.7)$ \\
\hline \multirow[t]{2}{*}{3} & Males & $48(42)$ & $38(33)$ & $13(11)$ & $16(14)$ & 115 (18) \\
\hline & Females & $9(12)$ & $24(31)$ & $32(42)^{*}$ & $12(15)$ & $77(7.9)$ \\
\hline \multirow[t]{2}{*}{4} & Males & $9(37)$ & $6(25)$ & $4(17)$ & $5(21)$ & $24(3.8)$ \\
\hline & Females & $1(4)$ & $10(36)$ & $8(28)$ & $9(32)$ & $28(2.9)$ \\
\hline
\end{tabular}

${ }^{*}$ Key for risk factors include age, gender, systolic blood pressure (at the time of the interview), treatment for hypertension (yes/no), diabetes (yes/no), smoking (yes/no), total blood cholesterol, high-density lipoprotein (HDL), 1: $p=0.02,2 p=0.004,3: p<0.001,4: p=0.02$, 
the proportion of women exceeded that of men. The 10 -year ASCVD risk scores found that 16\% ( $n=153)$ of participants in the age group 40-75 years have high risk. The risk was significantly low in women $(p<0.001)$; however, the age comparison revealed a greater number of women with high risk in the age group 60-75 years.

Diabetes mellitus and HTN were the primary factors contributing toward high ASCVD risk scores. Among the $16 \%(n=153)$ with high 10-year ASCVD risk, $44 \%$ of men and $71 \%$ of women had DM. Furthermore, among these individuals, 40\% (62 out of 153) had uncontrolled diabetes (HbA1c $>6.5 \%)$. Similarly, for HTN, 25\% ( $\mathrm{n}=38)$ had uncontrolled blood pressure $(>140 />90 \mathrm{~mm} \mathrm{Hg}$ ), without any significant gender difference. The high-risk lifetime ASCVD group showed that $13.5 \%$ (146 of 1081 ) had HbA1c $>6.5 \%$, whereas $12 \%$ of participants had uncontrolled HTN.

Table 4 shows the number of ASCVD risk factors by age categories. Many women (65.5\%) had one risk factor, whereas $38 \%$ of men had minimum 2 risk factors. The number of men with maximum risk factors belonged to the age group 30-39 years, whereas, in the remaining age groups (40-75 years), the number of women exceeded that of men (Table 4).

Discussion. In the high- and middle-income countries of the Middle East, there has been a rapid economic development leading to an increasing rate of DM from approximately $6 \%$ in 1990 to $>20 \%$ in $2012 .{ }^{17}$ In the KSA, conducted during 2007-2009, Al-Rubeaan et al, reported that the overall prevalence of DM among the Saudi population aged $\geq 30$ years was $25.4 \%(\mathrm{n}=4576)$, with $12 \%$ (1845 of 15,303$)$ being unaware of their disease. ${ }^{18}$ Although, the estimated prevalence of undiagnosed DM is considered to be far lower at $3.1 \%$ a systematic review found that there is further need for creating awareness about diabetes by integrating awareness campaigns in the main health systems. ${ }^{19}$ The epidemic behavior of DM prevalence in KSA might be explained primarily by ethnicity and genetic factors, accompanied by high consanguineous marriage rates. ${ }^{20}$ In general, there is a wide gender ratio difference across countries with regard to DM prevalence, and different biological, cultural, lifestyle, environmental, and socioeconomic factors have their impact on the predisposition, development, and clinical presentation of DM. ${ }^{21}$ Recently, the male gender has been considered as a risk factor for type 2 diabetes developments, with unclear reasons. ${ }^{22}$ Moreover, the majority of data from Western European or Asian descent populations suggest a slightly higher prevalence of type 2 diabetes among men than among women. ${ }^{23,24}$
In contrast to these results, the present study results demonstrated that DM prevalence is higher among women than among men. Such difference might be explained by having a higher obesity prevalence and more prone metabolic imbalance in women, in addition to a sedentary lifestyle. ${ }^{24}$ Review studies conducted on prevalence and risk factors of chronic diseases among women belonging to Gulf countries, reported that a significant increase in the prevalence of DM was observed after the year 2000, and found no significant gender difference pertaining to DM prevalence ${ }^{25,26}$

The estimated HTN prevalence in the present study was $18 \%$, with more women than men. Such prevalence is lower than that in a community-based local study published in 2007 at KSA, at $26.1 \%$ among people aged 30-70 years. ${ }^{27}$ However, in another study published in 2014, the prevalence rates of HTN and borderline HTN among Saudi individuals aged $\geq 15$ years were 15.2\% and $40.6 \%$, respectively. ${ }^{28}$ Methodological differences might explain the difference in the prevalence reported by above studies. The highest percentage of hypertensive Saudis in the present study were undiagnosed, and the largest proportion of those on treatment were not controlled, a finding consistent with that of $\mathrm{El}$ Bcheraoui et al. ${ }^{28}$ In contrast to previous studies, the prevalence of HTN was higher in women in the present study. A higher prevalence of HTN, diagnosed or undiagnosed, among men was also reported by Hanna et al in Panama. ${ }^{29}$ These gender differences in HTN prevalence are due to both biological and behavioral factors. ${ }^{30}$ Biological factors include sex hormones, chromosomal differences, and other biological gender differences that are protective against $\mathrm{HTN}^{30}$ It is worthy to mention here that such biological factors become evident during adolescence and persist through adulthood until women reach menopause, and at that point, the gender differences in HTN become smaller or even nonexistent, which might explain our finding that the peak of HTN prevalence was at age 50 years in women.

A complex difference exists between men and women in these key behavioral risk factors. ${ }^{31}$ Body mass index distribution varies by gender, and as in our findings, previous studies have found that women have a higher prevalence of obesity than men, especially high-grade obesity, and in contrast, men have a higher prevalence of overweight than women. ${ }^{32}$ In general, our data revealed that the overall prevalence of both overweight (31.7\%) and obesity $(51.7 \%)$ was extremely high at $83.6 \%$, being higher among women at $85.7 \%$ than among men at $78.7 \%$. Such prevalence is considered to be within the reported numbers in the Gulf Cooperation Council countries. ${ }^{33}$ It has been estimated that the prevalence 
of overweight ranges between $25 \%$ and $50 \%$ and the prevalence of obesity ranges between $10 \%$ and $50 \%$ and is found to be relatively higher in women showing an increase with age. ${ }^{33}$ Genetic predisposition, lack of outdoor physical exercise, and unhealthy lifestyle and dietary habits may play a role in this increasing metabolic illness, particularly in women. ${ }^{34,35} \mathrm{~A}$ recent conceptual model on global obesity has placed the Middle East, including Saudi Arabia, in stage 2 of obesity transition. According to the authors, in stage 2, the prevalence is high among adults and the gender and socioeconomic differences are narrowed for women. ${ }^{36}$ The transition stages can help policy makers identify the stage in which their country lies and make policy guidelines accordingly. Our study findings are in support of a previous study that found significant gender differences, with a greater number of women than men showing hypercholesterolemia. ${ }^{35}$ Moreover, al-Nuaim et al found that there was a progressive increase in hypercholesterolemia with age, reaching a maximum in the fifth and sixth decades for men and women, respectively. ${ }^{37}$

In the US, ASCVDs remain the leading cause of death, accounting for $31.3 \%$ of all deaths. ${ }^{38}$ Unfortunately, more than half of the present study participants had high lifetime ASCVD risk, and this is expected based on the high rates of CVD risk factors (obesity, diabetes, HTN, and hypercholesterolemia) reported in the study. Our results also demonstrated that overall, men have an increased risk for ASCVD than women, and that among men, the risk was higher at a younger age, which is consistent with a previously published study reporting that age and gender are independent and potential risk factors for CVD in adults. ${ }^{39,40}$ It is reported that male gender and age are the strongest risk factors for coronary artery disease (CAD). ${ }^{40}$ Gender differences in ASCVD risks are largely attributed to sex hormones and their associated receptors, where a protective effect of sex steroid hormones, particularly estrogen, on CVD risk in women has often been suggested..$^{41,42}$ Men generally develop CVD at a younger age and have a higher propensity of developing coronary heart disease than women, whereas women are at a higher risk of developing stroke, which often occurs at an older age. ${ }^{42}$ In contrast, the effects of exogenous estrogen on the risk of developing ASCVDs in postmenopausal women were not beneficial and suggested that supplementation could even increase the risk for stroke among women with a history of CVD. ${ }^{43}$ However, in another study, Rossouw demonstrated that estrogen could protect against CHD but not stroke among women within 5 years of menopause. ${ }^{44}$ Based on the conception that women are "protected" against CVDs, the risk for heart disease in women is often underestimated.

In general, women with clinically manifesting CHD are older than men, with a higher expression of cardiovascular risk factors. ${ }^{45}$ After menopause, central obesity with an increase in visceral fat occurs more frequently, with increased metabolic syndrome components in women compared with aging men. ${ }^{40}$ Previous studies have reported a steep rise in systolic blood pressure in aging women compared with men, and authors had related it to the decline in estrogen levels during menopause transition..$^{42}$ Moreover, it was found that the relative risk for hypercholesterolemia is lower in women than men at a younger age, whereas in menopause, the total cholesterol and LDL levels increases significantly. ${ }^{44}$

Study limitations. The results of our study are robust as the sample represents the capital city, Riyadh, comprising of different ethnicities, social classes, and working population. Moreover, blood samples were transported and tested as per standard protocols. However, we are limited in generalizing the results to the rural areas. High-risk patients like patients with a history of myocardial infarction, previous PCI, or CABG may be underrepresented in this study, as such patients will have a follow-up in tertiary care centers and not in primary health care centers.

More effort should be directed toward the prevention and early detection of chronic diseases among women aged 50-59 years. Strategies to increase awareness and reduce the burden of CVD through multiple interventional programs should be implemented targeting obesity, tobacco use, physical inactivity, diet, and screening for chronic diseases such as DM, hypercholesterolemia, and CVDs.

In conclusion, chronic diseases were prevalent among both men and women, with men aged $>30$ years being at high risk, whereas the risk in women tended to increase from age 40 years but reached the peak at age $>50$ years. Women in the age group 50-59 years with multiple risk factors are at more risk of developing CVDs than men of same age. Obesity was more prevalent in women than men. A similar trend was observed for lifetime ASCVD scores; however, the 10-year ASCVD risk increased with increasing age.

Acknowledgment. Authors would like to thank the Deanship of Scientific Research, Research Chairs Program, King Saud University, Riyadh, Saudi Arabia for the funding and support. We would like to acknowledge the cooperation extended by the Primary Health Care Centers in conducting this study. We acknowledge the support extended by the Central Laboratory, King Saud University Medical City, Riyadh, Saudi Arabia in conducting the blood tests. The authors thank the 
Deanship of Scientific Research and Research support and services unit at King Saud University for their technical support and facilitation in acquiring services for English language editing.

\section{References}

1. Roth G, Abate D, Abate K, Abay S, Abbafati C, Abbasi N et al. Global, regional, and national age-sex-specific mortality for 282 causes of death in 195 countries and territories, 1980-2017: a systematic analysis for the Global Burden of Disease Study 2017. The Lancet 2018; 392: 1736-1788.

2. United Nations Interagency Task Force on the Prevention and Control of Non-communicable Diseases. The Investment Case for Non-communicable Disease Prevention and Control In the Kingdom of Saudi Arabia: Return on Investment Analysis \& Institutional and Context Analysis, August 2017. Geneva (CH): World Health Organization; 2018

3. Herzallah H, Antonisamy B, Shafee M, Al-Otaibi S. Temporal trends in the incidence and demographics of cancers, communicable diseases, and non-communicable diseases in Saudi Arabia over the last decade. Saudi Med J 2019; 40: 277-286.

4. Roger V, Go A, Lloyd-Jones D, Benjamin E, Berry J, Borden W, et al. Heart disease and stroke statistics-2012 Update. Circulation 2012; 125: e2-e220.

5. Benjamin E, Virani S, Callaway C, Chamberlain A, Chang A, Cheng S, et al. Heart Disease and Stroke Statistics-2018 Update: A Report From the American Heart Association. Circulation 2018; 137: e67-e492.

6. Al-Rubeaan K, Bawazeer N, Al Farsi Y, Youssef A, Al-Yahya A, AlQumaidi H, et al. Prevalence of metabolic syndrome in Saudi Arabia - a cross sectional study. BMC Endocrine Disorders 2018; 18: 16.

7. Al-Zakwani I, Al-Mahmeed W, Arafah M, T. Al-Hinai A, Shehab A, Al-Tamimi O et al. Control of Risk Factors for Cardiovascular Disease among Multinational Patient Population in the Arabian Gulf. Curr Vasc Pharmacol 2016; 14: 374-381.

8. Kontis V, Mathers C, Rehm J, Stevens G, Shield K, Bonita R et al. Contribution of six risk factors to achieving the $25 \times 25$ noncommunicable disease mortality reduction target: a modelling study. The Lancet 2014; 384: 427-437.

9. Goh LG, Dhaliwal SS, Welborn TA, Lee AH, Della PR. Anthropometric measurements of general and central obesity and the prediction of cardiovascular disease risk in women: a cross-sectional study. BMJ Open 2014; 4: e004138.

10. Al-Rubean K, Youssef AM, AlFarsi Y, Al-Sharqawi AH, Bawazeer N, AlOtaibi MT, AlRumaih FI, Zaidi MS. Anthropometric cutoff values for predicting metabolic syndrome in a Saudi community: from the SAUDI-DM study. Ann Saudi Med 2017; 37: 21-30.

11. McKibben R, Al Rifai M, Mathews L, Michos E. Primary prevention of atherosclerotic cardiovascular disease in women. Curr Cardiovasc Risk Rep 2016; 10: 1.

12. Lloyd-Jones D, Leip E, Larson M, D’Agostino R, Beiser A, Wilson $\mathrm{P}$ et al. Prediction of lifetime risk for cardiovascular disease by risk factor burden at 50 years of age. Circulation 2006; 113: 791-798.

13. Kandula N, Kanaya A, Liu K, Lee J, Herrington D, Hulley S, et al. Association of 10-year and lifetime predicted cardiovascular disease risk with subclinical atherosclerosis in South Asians: Findings from the mediators of atherosclerosis in South Asians living in America (MASALA) Study. J Am Heart Assoc 2014; 3: e001117.
14. World Health Organization. Waist Circumference and Waist-Hip Ratio Report of a WHO 525 Expert Consultation Geneva (SW): World Health Organization. [cited 2008 December 8-11]. Available from: https://www.who.int/ publications/i/item/9789241501491

15. Friedewald W, Levy R, Fredrickson D. Estimation of the concentration of low-density lipoprotein cholesterol in plasma, without use of the preparative ultracentrifuge. Clin Chem 1972; 18: 499-502.

16. American College of Cardiology. ASCVD calculator. Available from: https://tools.acc.org/ldl/ascvd_risk_estimator/index. html\#!/calulate/estimator/.

17. Scully T. Diabetes in numbers. Nature 2012; 485: S2-S3.

18. Al-Rubeaan K, Al-Manaa HA, Khoja TA, Ahmad NA, Al-Sharqawi AH, Siddiqui K, et al. Epidemiology of abnormal glucose metabolism in a country facing its epidemic: SAUDI-DM study. J Diabetes 2015; 7: 622-632.

19. Alanazi F, Alotaibi J, Paliadelis P, Alqarawi N, Alsharari A, Albagawi B. Knowledge and awareness of diabetes mellitus and its risk factors in Saudi Arabia. Saudi Med J 2018; 39: 981-989.

20. Al-Gazali L, Hamamy H, Al-Arrayad S. Genetic disorders in the Arab world. BMJ 2006; 333: 831-834.

21. Kautzky-Willer A, Harreiter J, Pacini G. Sex and gender differences in risk, pathophysiology and complications of type 2 diabetes mellitus. Endocr Rev 2016; 37: 278-316.

22. Tracey M, McHugh S, Buckley C, Canavan R, Fitzgerald A, Kearney P. The prevalence of Type 2 diabetes and related complications in a nationally representative sample of adults aged 50 and over in the Republic of Ireland. Diabet Med 2016; 33: 441-445.

23. Wändell $\mathrm{P}$, Carlsson A. Gender differences and time trends in incidence and prevalence of type 2 diabetes in Sweden-A model explaining the diabetes epidemic worldwide today?. Diabetes Res Clin Pract 2014; 106: e90-e92.

24. Nordström A, Hadrévi J, Olsson T, Franks P, Nordström P. Higher prevalence of type 2 diabetes in men than in women is associated with differences in visceral fat mass. J Clin Endocrinol Metab 2016; 101: 3740-3746.

25. Alshaikh MK, Filippidis FT, Al-Omar HA, Rawaf S, Majeed A, Salmasi AM. The ticking time bomb in lifestyle-related diseases among women in the Gulf Cooperation Council countries; review of systematic reviews. BMC Public Health 2017; 17: 536.

26. Aljefree N, Ahmed, F. Prevalence of cardiovascular disease and associated risk factors among adult population in the Gulf Region: A systematic review. Adv Public Health 2015; 2015: 1-23.

27. Al-Nozha MM, Abdullah M, Arafah MR, Khalil MZ, Khan NB, Al-Mazrou YY, et al. Hypertension in Saudi Arabia. Saudi Med J 2007; 28: 77-84.

28. El Bcheraoui C, Memish Z, Tuffaha M, Daoud F, Robinson $\mathrm{M}$, Jaber $\mathrm{S}$ et al. Hypertension and its associated risk factors in the Kingdom of Saudi Arabia, 2013: A national survey. Int J Hypertens 2014; 2014: 564679.

29. Hanna D, Walker R, Smalls B, Campbell J, Dawson A, Egede L. Prevalence and correlates of diagnosed and undiagnosed hypertension in the indigenous Kuna population of Panamá. BMC Public Health 2019; 19: 843.

30. Sandberg K, Ji H. Sex differences in primary hypertension. Biol Sex Differ 2012; 3: 7. 
31. Niskanen L, Laaksonen D, Nyyssönen K, Punnonen K, Valkonen V, Fuentes R, et al. Inflammation, abdominal obesity, and smoking as predictors of hypertension. Hypertension 2004; 44: 859-865.

32. Inoue Y, Qin B, Poti J, Sokol R, Gordon-Larsen P. Epidemiology of obesity in adults: Latest trends. Curr Obes Rep 2018; 7: 276-288.

33. Alhyas L, Mckay A, Balasanthiran A, Majeed A. Prevalences of overweight, obesity, hyperglycaemia, hypertension and dyslipidaemia in the Gulf: systematic review. JRSM Short Reports 2011; 2: 7.

34. Baird J, Jacob C, Barker M, Fall C, Hanson M, Harvey N et al. Developmental origins of health and disease: A life course approach to the prevention of non-communicable diseases. Healthcare 2017; 5: 14.

35. Abulmeaty M, Almajwal A, Almadani N, Aldosari M, Alnajim $\mathrm{A}$, Ali $\mathrm{S}$ et al. Anthropometric and central obesity indices as predictors of long-term cardiometabolic risk among Saudi young and middle-aged men and women. Saudi Med J 2017; 38: 372-380.

36. Jaacks L, Vandevijvere S, Pan A, McGowan C, Wallace C, Imamura $\mathrm{F}$ et al. The obesity transition: stages of the global epidemic. The Lancet Diabetes Endocrinol 2019; 7: 231-240.

37. Al-Nuaim A, Al-Rubeaan K, Al-Mazrou Y, Al-Attas O, Al-Daghari N. Prevalence of hypercholesterolemia in Saudi Arabia, epidemiological study. Int J Cardiol 1996; 54: 41-49.

38. Benjamin E, Blaha M, Chiuve S, Cushman M, Das S, Deo R, et al. Heart Disease and Stroke Statistics-2017 update: A report from the American Heart Association. Circulation 2017; 135: e146-e603.
39. Rodgers JL, Jones J, Bolleddu SI, Vanthenapalli S, Rodgers LE, Shah K, et al. Cardiovascular risks associated with gender and aging. J Cardiovasc Dev Dis 2019; 6: 19.

40. Vitale C, Fini M, Speziale G, Chierchia S. Gender differences in the cardiovascular effects of sex hormones. Fundam Clin Pharmacol 2010; 24: 675-685.

41. Garcia M, Mulvagh S, Bairey Merz C, Buring J, Manson J. Cardiovascular disease in women. Cir Res 2016; 118: 1273-1293.

42. George J, Rapsomaniki E, Pujades-Rodriguez M, Shah A, Denaxas S, Herrett E et al. How does cardiovascular disease first present in women and men? Circulation 2015; 132: 1320-1328

43. Boardman H, Hartley L, Eisinga A, Main C, Roqué i Figuls $\mathrm{M}$, Bonfill Cosp X, et al. Hormone therapy for preventing cardiovascular disease in post-menopausal women. Cochrane Database Syst Rev 2015; (3): CD002229.

44. Rossouw J, Prentice R, Manson J, Wu L, Barad D, Barnabei V et al. Postmenopausal hormone therapy and risk of cardiovascular disease by age and years since menopause. JAMA 2007; 297: $1465-1477$

45. Leening M, Ferket B, Steyerberg E, Kavousi M, Deckers J, Nieboer D, et al. Sex differences in lifetime risk and first manifestation of cardiovascular disease: prospective population based cohort study. BMJ 2014; 349: g5992. 